\title{
AN INITIAL SIMULATION MODEL FOR AIDING POLICY ANALYSIS IN URBAN INSURGENCIES
}

\author{
Edward G. Anderson Jr. \\ McCombs School of Business \\ 1 University Station B6500 \\ University of Texas \\ Austin, TX 78733, U.S.A.
}

\begin{abstract}
This paper aims to demonstrate the potential for using the system dynamics computer simulation methodology to gain insight into the evolution of insurgencies. In particular, it extends a prior system dynamics model of insurgencies containing the dynamic mechanisms of incident suppression, insurgent creation, and war weariness to also embrace the factors of unemployment, propaganda, finance, and weapons supply chains. Numerous policy simulation tests are then conducted using as a base case a calibration of the model to the Anglo-Irish War of 19161921 to examine the effects of various policies aimed at suppressing insurgencies. The paper suggests that none of these policies - when implemented at achievable levelswill be nearly as successful in stopping an insurgency as a coordinated bundle of all of these policies together. The paper then concludes by proposing how a simulation model might be further developed to assist policy makers in managing current insurgencies throughout the world.
\end{abstract}

\section{INTRODUCTION}

Insurgencies have arguably been the dominant mode of warfare (at least in terms of numbers of conflicts) during the past fifty years (O’Neill 1990). A partial list of nations suffering from insurgent warfare (also known as guerilla conflicts, asymmetric warfare, or low intensity conflicts would include the Philippines, Afghanistan, Chechnya, Iraq, Kashmir, Yemen, Djibouti, Columbia, and Sri Lanka (Kaplan 2005, Economist 2005a, Economist 2005b, Economist 2006). Many of these insurgencies have religious or ethnic overtones, although some do not (O'Neil 1990). For example, drug trafficking appears to be a key driver in Columbia (Kaplan 2005) and political ideology in Peru (O’Neill 1990).

Historically speaking, guerilla warfare itself is nothing new. Raiding, from which "guerilla" warfare developed, in fact predates conventional warfare (Keegan 1994). However, its marriage to a revolutionary ethic began only in the eighteenth century with the American
Revolution (Beckett 2001). Its full development as an effective complement, and sometimes replacement, for conventional warfare is a development only of the past century. This occurred for a number of reasons. The wide availability of asymmetric weapons in which the insurgent can kill targets without revealing himself began with the development of smokeless-powder, high-velocity rifles just prior to 1900. At the same time, urbanization became much more widespread in many countries, which notoriously hampers the effectiveness of conventional operations. Financial and commercial networks became sufficiently sophisticated that expatriates and other groups in one nation could easily fund and supply with weapons insurgent organizations in a second nation overseas. Finally, the rise of decentralized, rapid, mass communications enabled propaganda by governmental and non-governmental organizations (such as insurgents) to develop into a nuanced and powerful art.

These factors taken together make the management of insurgencies more difficult than in former times. Hence the purpose of this paper is to sketch out a "proofof-concept" for a methodology to use computer simulation as a decision support tool for managing insurgencies. In particular, we will attempt to capture the essential dynamics of insurgency at a strategic level to provide insight into how insurgencies evolve in response to different policies. To this end, we shall employ the system dynamics methodology, which has shown itself to be a useful methodology for modeling the effects of policy on large organizational systems (Forrester 1958, Sterman 2000) and in particular the simulation work of Anderson (2006) on urban insurgencies. Anderson's work developed a model of the Anglo-Irish war of 1916-21, considered by many military historians to be perhaps the first modern urban insurgency (Keegan 2001). In particular, we will extend that model to include the effect of economic policies, propaganda, and finance and arms embargos. We shall also examine the effects of several policy interventions upon the simulated insurgency in this extended model. If by pursuing this course, we can generate a number of interesting policy insights, then we can de- 
velop reasonable confidence that the system dynamics approach is worthy of further study as a potential policy analysis tool for managing insurrections.

The remainder of the paper is organized as follows. Section 2 presents the model structure. Section 3 describes the parameter and policy sensitivity analyses. Finally, Section 4 discusses the implications of this research for further model development.

\section{THE MODEL}

For the present, we restrict our interest to insurgencies that (1) are primarily urban rather than rural and (2) in which the counter-insurgent's seat of government exists in a different nation from that in which the insurgency is taking place. Hence, we shall base our analysis on the model presented in Anderson (2006) rather than some of the other excellent work on insurgencies using the system dynamics method, such as Coyle (1985), which focuses on rural insurgencies. However, there have been some slight changes in the parameterization from Anderson (2006) to improve the accuracy of simulation. (A fully documented listing of the equations behind the simulation is available from the author.)

From many accounts (Gurr 1970, Beckett 2001, O’Brien 1990, Kautt 1999, English 2003, U.S. Marine Corps 1940) the following factors-incident suppression, insurgent creation, war-weariness, finance, and weapons availability-seemed decisive in the Anglo-Irish War as well as in many other urban insurgencies.

The remainder of the section will briefly present the causal mechanisms behind the various dynamic factors active in urban insurgencies as well as describe some associated behaviors in detail.

\subsection{Incident Suppression}

Consider the basic insurgency suppression structure in Figure 1 drawn from Anderson (2006).

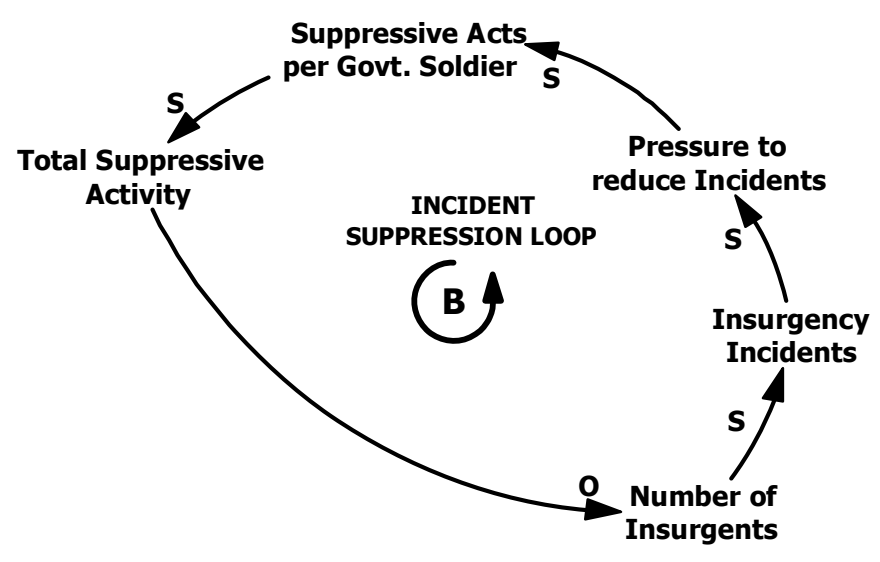

Figure 1: Insurgency suppression loop
For the remainder of this paper, we shall use the term "government" to refer to the incumbent regime, which the insurgents are trying to displace. Figure 1 contains what is referred to in the system dynamics methodology as a causal-loop diagram. Following system dynamics conventions, each arrow in the diagram represents a link of causation between two variables. For example, ceteris paribus, an increase in the number of active insurgents will result in an increase in the number of incidents committed by those insurgents (including raids, snipings, acts of arson, bombings, or other incidents) directed at elements of the government. Because any change (whether an increase or decrease) in the number of insurgents will ceteris paribus result in a change in the number of incidents in the same direction, the arrow is labeled with an "S" next to it. (An "O" label next to an arrow indicates, in contrast, that the two linked variables always move in opposite directions.) Finally, because it feeds back on itself, the entire chain of variables in Figure 1 is known as a "causal loop" or, more simply, a loop. Causal loops are the building blocks of all system dynamics models.

To examine the incident suppression loop in Figure 1 more closely, consider the lower right-hand side of Figure 1 , beginning with the number of insurgents. Each of these insurgents commits a number of insurgency incidents per month. Over time, the rate of incidents builds up pressure upon the government to reduce the number of incidents. This pressure leads to an increase in the number of house searches, arrests, detentions, or other activities to suppress the insurgency. Over time, this activity will eventually reduce the number of active insurgents. Note the "O" next to the arrow linking total suppressive activity and number of insurgents, indicating that an increase (or decrease) in interference will result in a pressure to decrease (or increase) in insurgents. Because of the chain of variables in the causal loop, any increase in the number of insurgents will ceteris paribus eventually result in a pressure to reduce (or vice versa) that same variable. Because of this behavior, this sort of loop is termed a "balancing loop." Balancing loops are marked within a causal-loop diagram by a "B" inside a circular arrow. Note that a short delay in this loop exists between pressure to reduce incidents and suppressive acts per government soldier, because of the time needed to implement any new suppressive policies. However, the delay is not marked in this causal loop because it is relatively short in comparison with delays contained within other loops in the model.

Figure 2 presents the typical behavior of a simulation of the incident suppression loop in isolation from all other effects. However, for this particular run, all other effects in that calibrated model have been deactivated. The run begins with 1000 insurgents, which in the absence of any other effects, are quickly either detained by government authorities or "retire" of their own accord by returning to civil life. Note that this and all other simulations pre- 
sented in this model assume that "Month 0" occurs in January 1919 as that is when the insurgency phase of the conflict is traditionally dated as beginning (Kautt 1999).

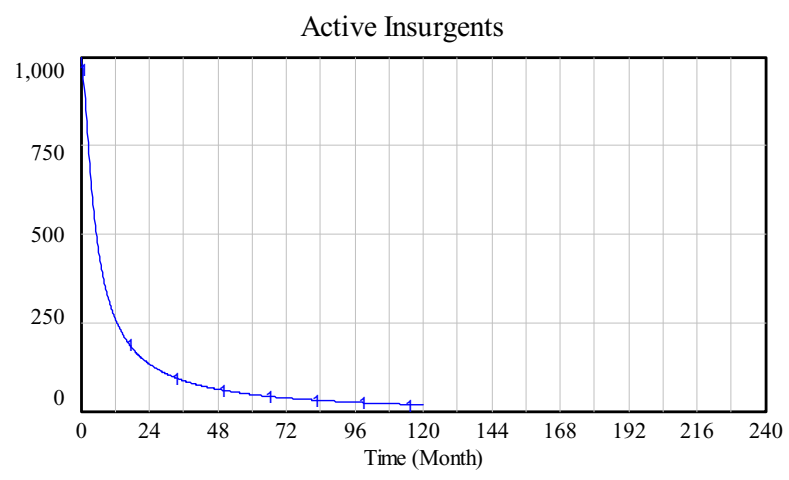

ACTIVE INSURGENTS : Suppression_Loop_Only $1,1,1,1,1$ insurgents

Figure 2: Simulated active insurgents vs. time when only the insurgent loop is active.

\subsection{Insurgent Creation}

However, the results of Figure 2 are misleading in isolation because other causal loops are also active in the system. The one most often noted in insurgencies is the insurgent creation loop presented in Figure 3, which is drawn from Anderson (2006). This is the loop thought responsible for a tremendous expansion or "snowball effect" in size of insurgent forces in many conflicts. It was certainly active in the Anglo-Irish War, particularly after 1918 (Kautt 1999).

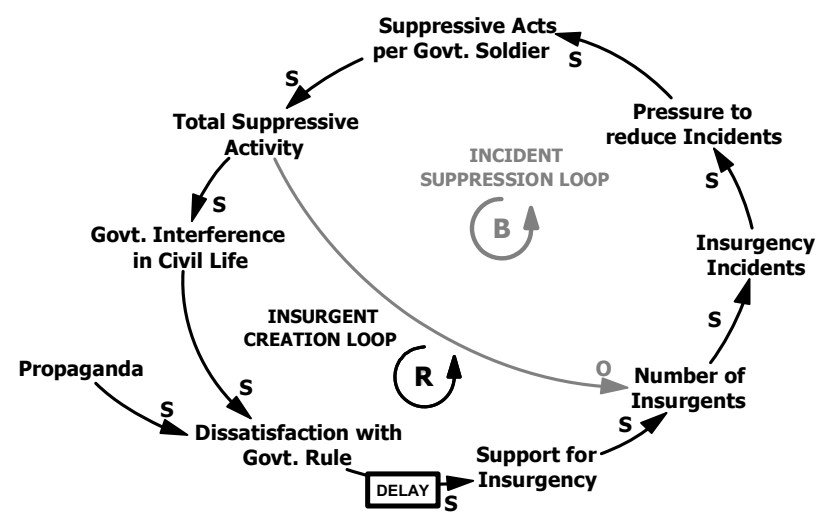

Figure 3: Addition of insurgent creation loop

In this loop, total suppressive activity by the government, while leading to the suppression of current insurgents, also necessitates interference in the civil life of the populace, leading to popular dissatisfaction with the government. This dissatisfaction leads to popular support for the insurgency and, hence, new individuals joining the insurgency. This creates the potential for a vicious cycle be- cause, ceteris paribus, any increase in the number of insurgents will lead to more incidents by the insurgents and hence more pressure to reduce incidents by the government. This pressure will result in a greater interference in civil life, dissatisfaction with government rule, and popular support for the insurgency. This completes the causal loop by increasing the number of insurgents still more. Because any change in the number of insurgents ultimately reinforces itself, this sort causal loop is termed a "reinforcing loop" and is marked with an " $\mathrm{R}$ " inside a circular arrow in the diagram. Reinforcing loops are most typically the engines of growth in system dynamics models.

A further wrinkle in this causal loop is that, while some of the effect of popular dissatisfaction on increasing insurgents will occur immediately, the full force effect of dissatisfaction will take some time to percolate through the system. The reason for this is that satisfaction with any government is more likely to fall under a prolonged regime of unpopular government activity than under a short one (Alagappa 1995). In other words, popular satisfaction - or lack thereof - with the government has some inertia. These delays (or inertias) in the model are marked by a rectangle containing the word "delay" between Dissatisfaction with Government Rule and Support for Insurgency. The net effect of this delay is to keep the vicious cycle of the insurgent creation loop from immediately spiraling out of control once it is set in motion.

Finally, an additional "benefit" for the insurgents is that widespread sympathy to the insurgency among the populace allows the insurgents greater mobility and enables them to more easily evade capture. This factor will also lead to a greater number of insurgents over the long run.

Figure 3 also shows the potential effects of propaganda, in which either the government or the population attempts to manipulate popular opinion to their own advantage.

The effect of the reinforcing loop of insurgent creation is shown in Figure 4. Instead of the incident suppression loop immediately decreasing the number of insurgents as in Figure 2, the number of insurgents actually increases in Figure 4 because the insurgent creation loop is activated. However, the full effect of the loop is not felt for eighteen months because of the inertia in public opinion and the time it takes for potential insurgents to become active. However, after eighteen months, the mass influx of new insurgents abates. In fact, the drop in the number of simulated insurgents is slowed only by new potential insurgents becoming of age to actually fight, partially balancing the loss of those insurgents who are captured by government forces. 
Active Insurgents

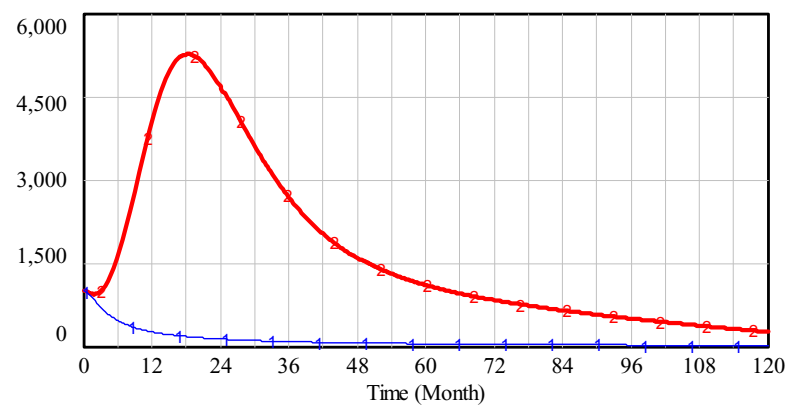

ACTIVE INSURGENTS : Suppression_Loop_Only $1,1,1,1,1-1$ Insurgents

Figure 4: The simulated effect of the insurgent creation loop on active insurgents.

\subsection{War Weariness}

The structures in Figure 3 did not account for how an insurrection ultimately ends. Figure 5 adds a troop escalation loop and a war-weariness loop to the model.

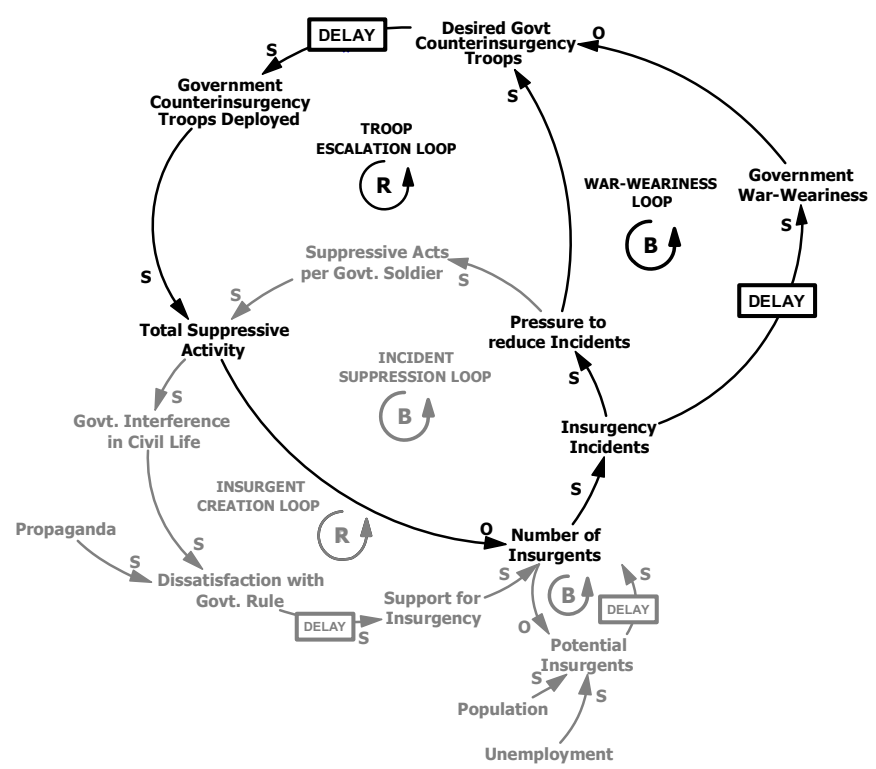

Figure 5: War weariness and troop escalation loops

In the troop escalation loop, as the pressure to reduce incidents increases, the government desires to increase the number of troops involved in counter-insurgency activities. Actually obtaining these troops involves the issuance of orders, arrangement of logistics, and actual shipment from the home country. This creates a substantial delay. Troops may also be shipped out of the country in which the insurgence is occurring, however, as the government becomes weary of the insurgency and "cuts its losses." This loop is marked as a balancing loop because it seems to come into effect only once the insurgent creation loop has begun to dominate the model.
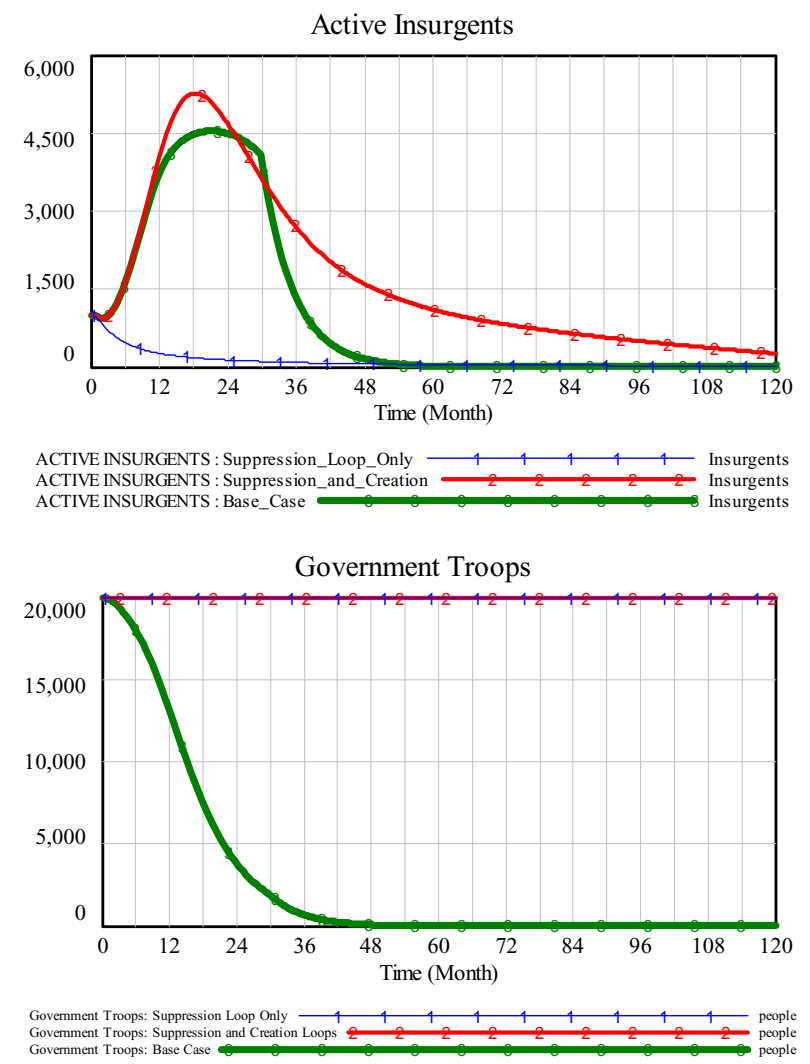

Figures 5 and 6: Number of simulated insurgents and government troops with war-weariness loop active

Note that the simulated number of insurgents in Figure 6 falls more slowly than the number of government troops. In fact, the number of simulated insurgents does not begin to fall in earnest until after the government withdrawal of troops. Even then, however, the demobilization takes some time. One could imagine that it would take a while for the insurgents to demobilize if for no other reason than that there is likely no extant procedure to muster them out.

\subsection{Population Growth and Unemployment}

At this point, we begin to extend the model just presented to enable policy and sensitivity testing in the next section. In particular, Figure 5 also shows the impact of population dynamics and unemployment upon the model. Presumably, if the population growth rate declines or unemployment drops, the number of young persons (generally, though not exclusively male) who are physically capable of participating in an insurgency and otherwise unoccupied will, ceteris paribus, increase. With time, one would expect this to increase the number of active insurgents in the simulation. 


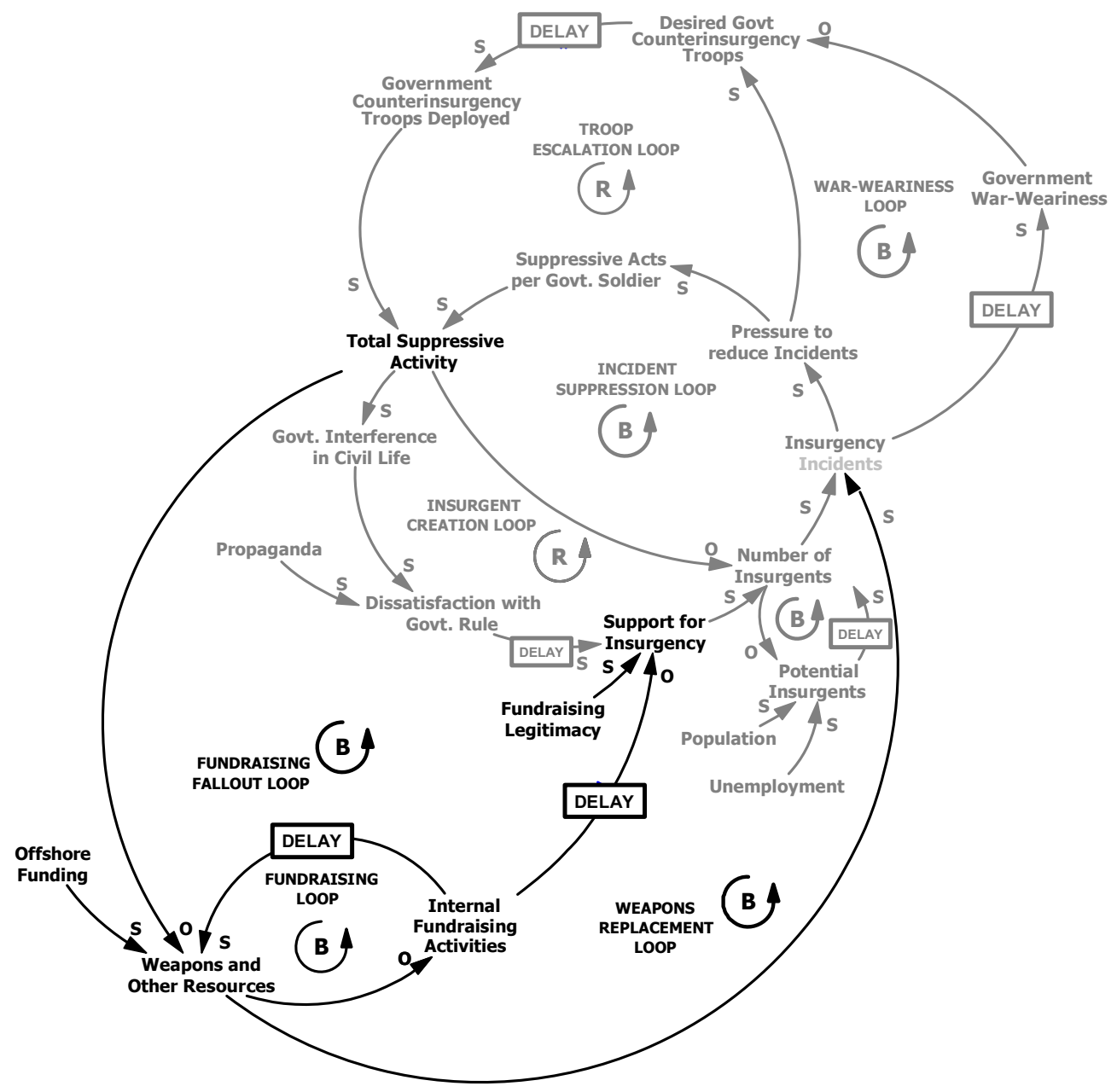

Figure 7: Weapons replacement \& fundraising loops

\subsection{Weapons and Finance}

Figure 7 presents the effects of weapons stockpiles and finance (in the form of fundraising activity) upon the model. Grynkewich and Reifel (2006) examined fundraising and popular support for insurgencies in detail in their model of the Salafist Group for Preaching and Combat (GSPC as known by its initials in French), currently active in North Africa. For our purposes, we shall adapt their work by simplifying their financial sector down to its essentials and then extend it to capture its impact upon the model's extant structure.

In the weapons replacement loop, suppressive activities reduce the number of weapons available to the insurgents. As weapons are reduced, the ability of the insurgents to create insurgent incidents also declines. Ultimately, if there are no funds to replace the weapons stockpile, the number of incidents will reduce to zero, and the insurgency will become dormant. To avoid this, the insurgent group will ideally acquire either funds or weapons from a sympathetic government or expatriate community. Otherwise, they will have to raise funds inside their own nation. With time this "fundraising" activity will replenish the weapons stockpile as shown in the fundraising loop and, hence, reestablish the insurgents' capability to create incidents. However, because insurgent groups often must resort to extortion, drug production, kidnapping, or other unpopular practices to raise funds, such activity may erode their popular support (Grynkewich and Reifel 2006, Kaplan 2005). This in turn will hamper the insurgency, ceteris paribus, by reducing (1) insurgent recruitment and (2) the ability of active insurgents to evade capture by hiding among a sympathetic populace. These effects are shown in the fundraising fallout loop in Figure 7.

During the Anglo-Irish War, the financial creativity of Michael Collins, the finance minister for the insurgent 
Irish government, as well as outside contributions from the United States kept the fundraising fallout loop inactive until the truce of 1921 (Kautt 1999). (Note that there is some dispute about this by historians, see e.g. Costick 1996. In the author's experience, this disagreement is typical. At best, different estimates of insurgent troops and related data agree only approximately. Often they differ by an order of magnitude.) However, lack of weapons has exercised a decisive impact on other occasions in Irish history (including the Irish rebellion of 1798). To show what the potential effects of a lack of weapons might be, the model was modified to account for the loops shown in Figure 7. The base case from the previous section is then compared with simulations of two levels of internal, unpopular fundraising in Figure 8.
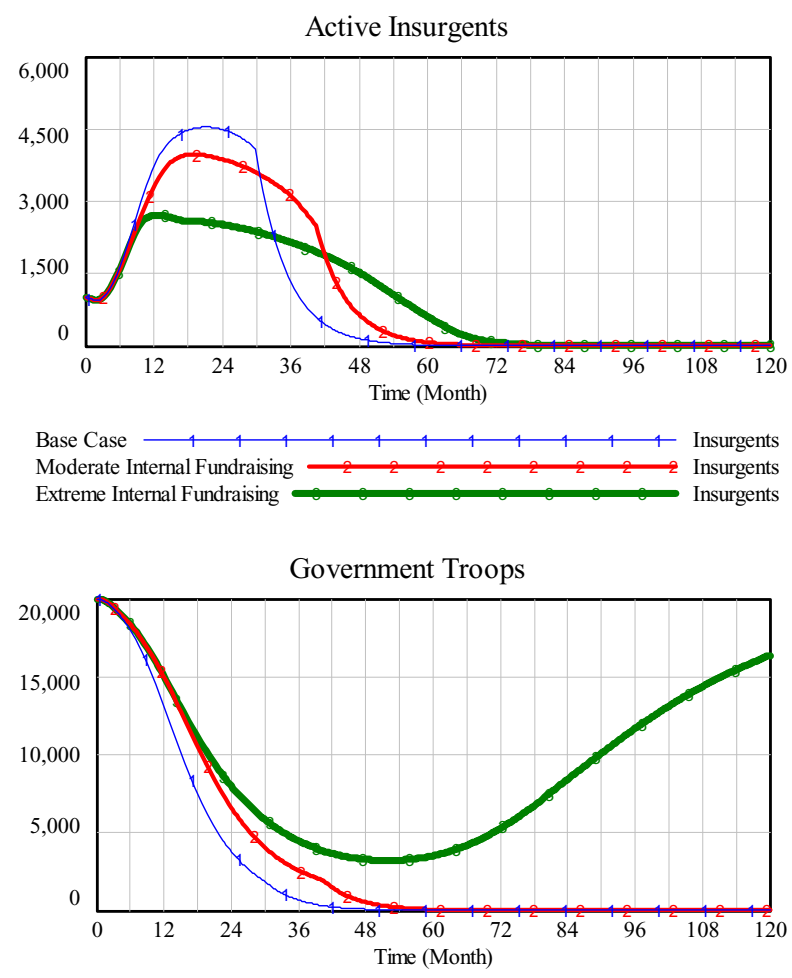

Government Troops: Base Case $4 \quad \begin{array}{lllllllll}1 & 1 & 1 & 1 & 1 & 1 & 1 & 1 & 1\end{array}$ people Government Troops: Moderate Internal Fundraising

Figure 8: The Effect of internal fundraising on insurgent and government troop levels

Under the base case, government troops are pulled out in month 30 . However, when a moderate level of internal, unpopular fundraising activity is required, simulated insurgent levels are reduced and the government is not forced to withdraw until month 43 , over a year later than in the base case. If a more extreme level of internal, unpopular fundraising is pursued, then the simulated government forces are never required to leave and in fact actually increase once progress occurs in reducing insurgent activity beginning in month 50 . This leads to the simu- lated insurgency being completely extinguished in month 72. This is particularly interesting because Anderson (2006) showed that under many model parameters, a "smoldering insurrection" behavioral mode may arise in which the government is never overthrown but neither is the insurgency ever eliminated.

To summarize: in this section, a system dynamics model based upon incident suppression, insurgent creation, war weariness, population demographics, and fundraising activity was developed. Further, several simulations explored the individual contribution of each of these factors to the evolution of a typical insurgency.

\section{POLICY SENSITIVITY ANALYSIS}

Because the ultimate aim of this paper is to determine whether the system dynamics methodology can be used to aid policy makers, we will explore the sensitivity of the model developed in the previous section to a limited set of parameter and policy changes The goal of this exploration is to determine whether any intriguing results arise, not to determine an optimal insurgency suppression strategy that is efficacious in all insurgencies.

Previously, Anderson (2006) established the potential efficacy of "military operations other than warfare" to extinguish insurrections by means of winning popular support and improving intelligence concerning insurgent activities. This was accomplished by means of such activities as running dental and medical clinics (with numerous intelligence personnel listening in to all the resulting conversation). However, a number of other interesting policies can now also be explored because of the extensions in the model introduced in Section 2.

\subsection{Economic Stimulation}

Ultimately, the strength of the insurgents rests upon the number of young people willing to join the insurgency. Many of these individuals are available because they are unemployed. If there were some way to reduce the unemployment among young people, what might be the effect upon an insurgency? A simulation of active insurgents under a moderate economic stimulus resulting in a reduction of 50 percent of the available pool of potential insurgents and a more aggressive policy that results in a 75 percent reduction is shown along with the base case in Figure 9. 


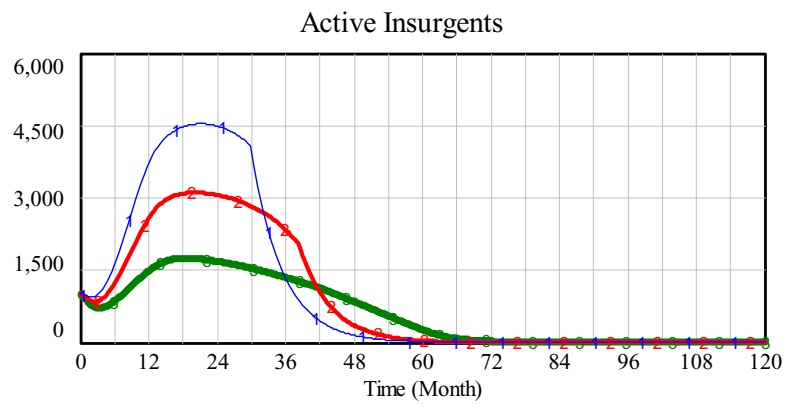

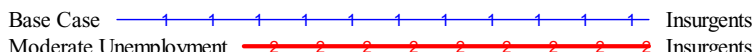
Moderate Unemployment $\frac{2}{2} z_{2} z_{2} z_{2} z_{2}{ }_{2} \geq$ Insurgents

Figure 9: Impact of economic stimulation

An economic stimulus sufficient to reduce the pool of simulated potential insurgents by 25 percent (the moderate unemployment scenario) leads to a less active insurrection. However, the insurgency remains ultimately successful, with a simulated government pullout in month 38 . An economic stimulus sufficient to reduce the available pool of potential insurgents by 50 percent (the low unemployment scenario) will, however, lead to a collapse in the insurgency and, hence, no government pullout. However, an economic stimulus capable of reducing the potential insurgent pool by fifty percent may be difficult to achieve. Hence, while an economic stimulus may - at least in the base scenario calibrated to the Anglo-Irish Warameliorate an insurgency, it appears that it may not be effective in actually extinguishing it.

\subsection{Population Growth}

A similar question might be asked about population growth. A regime of lower population growth might suggest that there would be less young people liable to join the insurgent pool. To test this, a simulation in which no population growth occurs, rather than the 3 percent annual population growth in the base case is presented in Figure 10.

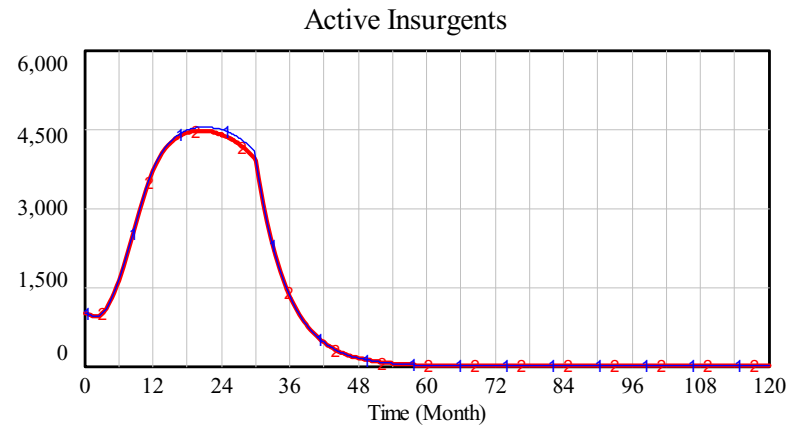

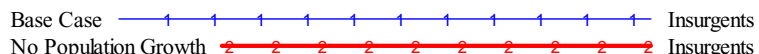

Figure 10: Effect of no population growth
The no population growth simulation shows very little effect on the number of simulated active insurgents. This is probably due to the insurrection, which the model is calibrated to, being successful in a short number of months. Hence, the effect on new insurgents joining the cause as they come of age is rather slight.

\subsection{Propaganda}

The Anglo-Irish War was peculiar in that the British government did not employ propaganda to attempt to justify their cause to the populace in Ireland. It would be of interest to test whether this might have made any difference in the insurrection's ultimate outcome. To simulate an effective propaganda campaign, we reduce the impact of suppressive acts upon popular dissatisfaction with the government by 10 percent (the moderate propaganda effect scenario) and 25 percent (the high propaganda effect scenario). The results are shown in Figure 11.
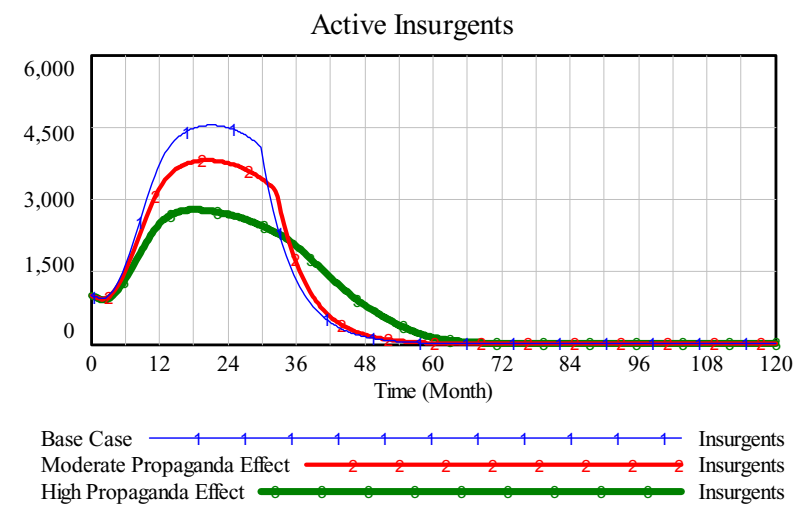

Figure 11: Effect of government propaganda

If a high propaganda effect level could be achieved, simulated insurgent activity would be reduced, and no government withdrawal would occur. Again, however, the likelihood that propaganda could impact dissatisfaction levels with the government may be overly ambitious. Unfortunately, while the moderate propaganda scenario does reduce insurgent activity, it only delays the government pullout by approximately 3 months. So, at least with this set of simulated parameters, reasonably attainable propaganda effects in isolation may not be sufficiently effective to end the insurgency.

\subsection{Combined Policy}

In Anderson (2006), one of the findings was that achievable policies rarely defused the insurgency in isolation. Rather policy bundles, such as military operations other than warfare, which combine several policies, were necessary. The same also seems to be true of the policies examined in this paper. Any achievable policy in isolation can ameliorate but not extinguish the simulated insurrec- 
tion. Hence, what can a combination of potentially achievable policies effect? The moderate propaganda or embargo on finance and/or weapons to the insurgents policies cannot stop the insurgency in isolation. However, combining the two policies can create a favorable result (Figure 12). A similar result may come about from combining the moderate propaganda and unemployment policies. These results yield great promise. While a "silver bullet" policy, such as reducing unemployment by 50 percent or creating a 100 percent effect arms embargo, may not be attainable, combinations of less ambitious policies might be.

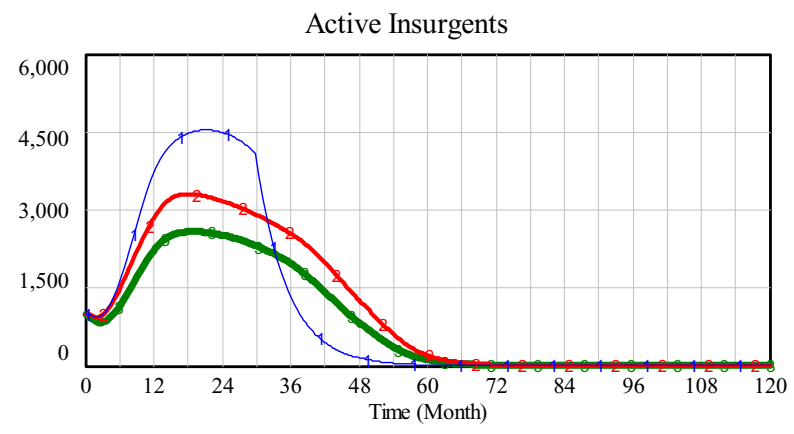

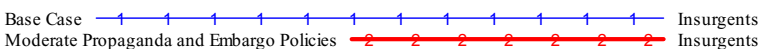
Moderate Propaganda and Embargo Policies

Figure 12: Effect of policy bundles

\section{DISCUSSION}

The aim of this paper was to demonstrate the potential of system dynamics to aid policy makers in developing better insights into the dynamic behavior of insurgencies. In particular, Section 2 took a model derived from Anderson (2006) embracing the three causal loops of insurgency suppression, insurgency creation, and war weariness, and added in the effects of economics, finance, and weapons availability. Section 3 went on to conduct several policy sensitivity tests with respect to economic stimulus, population growth, government propaganda, and weapons and financial embargos. The net result is that all of these scenarios, with the exception of no population growth, could ameliorate the insurgency in terms of insurgent activity. None of the policies, when realized at reasonably achievable levels, could, however, prevent eventual government withdrawal. Only a combination of attainable policies was sufficient.

Of course, all of these results are based on a simulation calibrated to one specific conflict. Yet, the results are intriguing and show the possibilities of using the system dynamics simulation methodology as a policy aid in modeling insurgencies.

There remains much work to do. In particular, the globablization of insurgencies, in which insurgencies in different geographic regions mutually support each other (Kaplan 2005, Jinnett 2006) must be examined. Addition- ally, nations in which there are multiple insurgency groups, each with different interests are clearly also of interest. Hence, once a general model for the evolution of an isolated, simple insurrection is developed, it will soon become necessary to network a number of such models together in order to represent the evolving global reality of interlinked and interdependent insurgencies that will characterize the twenty-first century.

\section{ACKNOWLEGEMENTS}

I would like to thank the following for influencing my thinking in this paper and on insurgencies in general: Col. Michael Jinnett (USMC, ret.), Mary Ann Anderson, Geoffrey Parker, Tom Johnson, Ignacio Martinez-Moyano, David Lane, Laura Black, Jeffrey Martin, Karan Ponnudurai, and Lt. Col. J. Ponnudurai (Royal Malaysian Air Force, ret.). Any mistakes or misconceptions in this paper is solely a result of my defective thinking, not theirs.

\section{REFERENCES}

Alagappa, M. 1995. Political Legitimacy in Southeast Asia: The Quest for Moral Authority. Stanford University Press: Stanford, CA.

Anderson, E. G. Jr. 2006. A Preliminary System Dynamics Model of Insurgency Management: The AngloIrish War of 1916-21 as a Case Study. In Proceedings of the 2006 International System Dynamics Conference, Nijmegen, the Netherlands.

Beckett, I. F. W. 2001. Modern Insurgencies and Counter-Insurgencies: Guerillas and their Opponents since 1750. Routledge: London.

Coyle, R. G. 1985. A systems description of counter insurgency warfare. Policy Sciences 18:55-78.

The Economist. 2005a. Stalling Tactics. November 5, 2005 44-45.

The Economist. 2005b. The Target was Peace. August 8, 200510

The Economist. 2006. A Thug in Charge: Chechnya Gets a New Prime Minister. March 11, 200648.

English, R. 2003. Armed Struggle: A History of the IRA. Oxford University Press: Oxford, UK.

Forrester, J. W. 1958. Industrial Dynamics: A Major Breakthrough for Decision Makers. Harvard Business Review 36(4):37-66.

Gurr, T. R. 1970. Why Men Rebel. Princeton University Press: Princeton NJ.

Grynkewich, A. and C. Reifel. 2006. "Modeling Jihad: A System Dynamics Model of the Salafist Group for Preaching and Combat Subsytem." Strategic Insights $5(8)$.

Hopkinson, M. 2002. The Irish War of Independence. McGill-Queen's University Press: Montreal.

Jinnett, M. 2006. Personal communication. 
Kaplan, R. D. 2005. Imperial Grunts: The American Military on the Ground. Random House: New York.

Kautt, W. H. 1999. The Anglo-Irish War, 1916-1921: A People's War. Praeger: Westport, CN.

Keegan, J. 1994. A History of Warfare. Vintage: London.

Keegan, J. and A. Wheatcroft. 2001. Who's Who in Military History. Routledge: New York.

Kostick, C. 1996. Revolution in Ireland: Popular Militancy 1917 to 1923. Pluto Press: London.

O'Neill, B. E. 1990. Insurgency \& Terrorism: Inside Modern Revolutionary Warfare. Brassey's: Washington.

Sterman, J. D. 2000. Business Dynamics: Systems Thinking and Modeling for a Complex World. McGrawHill/Irwin: New York.

U.S. Marine Corps. 1940. Small Wars Manual. Republished 2004 by Pavillion Press: Philadelphia.

\section{AUTHOR BIOGRAPHY}

Dr. Edward Anderson is an Associate Professor of Operations Management at the University of Texas McCombs School of Business. He received his doctorate from the Massachusetts Institute of Technology and his bachelor's degree with majors in history and electrical engineering from Stanford University. His research interests include outsourced product development and project management, supply chain management, national security policy, knowledge management, and computer simulation. He has published articles in Management Science, Production and Operations Management, and The System Dynamics Review. Dr. Anderson won the prestigious Wickham Skinner Early-Career Research Award from the Production and Operations Management Society. He is a senior editor of Production and Operations Management and has received research grants from the National Science Foundation, SAP, and Hewlett-Packard. Professor Anderson has consulted with Ford, Dell, Hewlett-Packard, Frito-Lay, and Atlantic-Richfield and holds three U.S. patents from his earlier career as an engineer at the Ford Motor Company. His web page can be found at $<w w w$. EdAnderson.org >, and his email address is $<$ ed@EdAnderson. org $>$. 